\title{
New tersilochines from the collection of Natural History Museum, London (Hymenoptera: Ichneumonidae: Tersilochinae)
}

\section{A.I. Khalaim}

\begin{abstract}
Khalaim, A.I. 2006. New tersilochines from the collection of Natural History Museum, London (Hymenoptera: Ichneumonidae, Tersilochinae). Zoosystematica Rossica, 14(2), 2005: 269-273.

Palpator sicilicus gen. et sp. n. from Italy and P. turpilucricupidus sp. n. from Tunisia, Tersilochus abyssinicus sp. n. and T. rusticulus sp. n. from Ethiopia, Zealochus gauldi sp. n. and Z. postfurcalis sp. n. from New Zealand are described. New data on the distribution of $Z$. supergranulatus Khalaim are presented. Keys to species of Palpator gen. n. and Zealochus Khalaim are given.
\end{abstract}

A.I. Khalaim, Zoological Institute, Russian Academy of Sciences, Universitetskaya nab. 1, St.Petersburg 199034, Russia.E-mail: hymenopt@zin.ru

The types of new species are deposited in the collections of the Natural History Museum (London, England, BMNH) and Zoological Institute RAS (St.Petersburg, Russia, ZISP).

\section{Palpator gen. n.}

Type species: Palpator sicilicus sp. n.

Description. Head and mesosoma mostly granulate and partly finely punctate. Head slightly prominent anteriorly (in female) and roundly narrowed posteriorly behind eyes in dorsal view; temple somewhat shorter than eye width (Fig. 1). Antenna with 19-21 segments, more or less filiform; flagellar segments slightly elongate or as long as wide. Maxillary palpi 4-segmented, longer than head height; labial palpi 3-segmented, short (Fig. 4). Mandible strongly tapered, long, triangular (lower tooth reduced and hardly discernible). Malar space short, not more than half of basal mandibular width.

Sternaulus weak, about half of mesopleuron length, situated in the anterior part of mesopleuron. Propodeum with shallow basal groove. Basal part of propodeum dorsally 0.4-0.6 times apical area length. Apical area rounded anteriorly; transverse carina and longitudinal carinae of apical area weak; longitudinal carinae not reaching transverse carina. Distance between propodeal spiracle and pleural carina 3-4 times spiracle diameter.

2-mcu vein of fore wing postfurcal (Fig. 7). Metacarp not reaching apex of fore wing. Width of pterostigma somewhat greater than length of first part of radial vein. Spurs of hind leg very short, curved.
First tergite long and thin; petiole trapeziform in transverse section. Glymma absent. Thyridia distinct, 2-2.5 times as long as wide. Ovipositor thin, upcurved, without teeth, slightly shorter than body.

Diagnosis. The new genus belongs to the genera group "Phradis" characterized by the first metasomal segment without glymma, propodeum with short basal area (or furrow), and 2-mcu vein interstitial or antefurcal (except for the new genus). It resembles the genus Heterocola in the long maxillary palpi, but differs in 2-mcu vein postfurcal and lower tooth of mandible reduced (mandible triangular).

\section{Key to species of Palpator gen. n.}

1. Petiole of first tergite distinctly striate dorsally and laterally. Malar space about half of basal mandibular width. Hind tibia with dark band near apex. Ovipositor with very shallow dorsal subapical depression (Fig. 8), weakly upcurved ........ P. sicilicus sp. n.

- Petiole of first tergite entirely smooth. Malar space very short, mandible almost adjoin to lower orbit of eye. Hind tibia yellowish, without dark band. Ovipositor without distinct dorsal subapical depression (Fig. 9), stronger upcurved . . . . . . . . . . . . . $\ldots \ldots \ldots \ldots \ldots$ P. turpilucricupidus sp. n.

Palpator sicilicus sp. n.

(Figs 1, 4, 7, 8)

Holotype. o, Italy, Sicily, Segesta, 17.IV.1931, G.J. Kerrich (BMNH).

Description. Female. Body length about $3.6 \mathrm{~mm}$. Head $0.74 \mathrm{~mm}$ wide, slightly prominent anteriorly and roundly narrowed posteriorly behind eyes in dorsal view (Fig. 1). Temple some- 

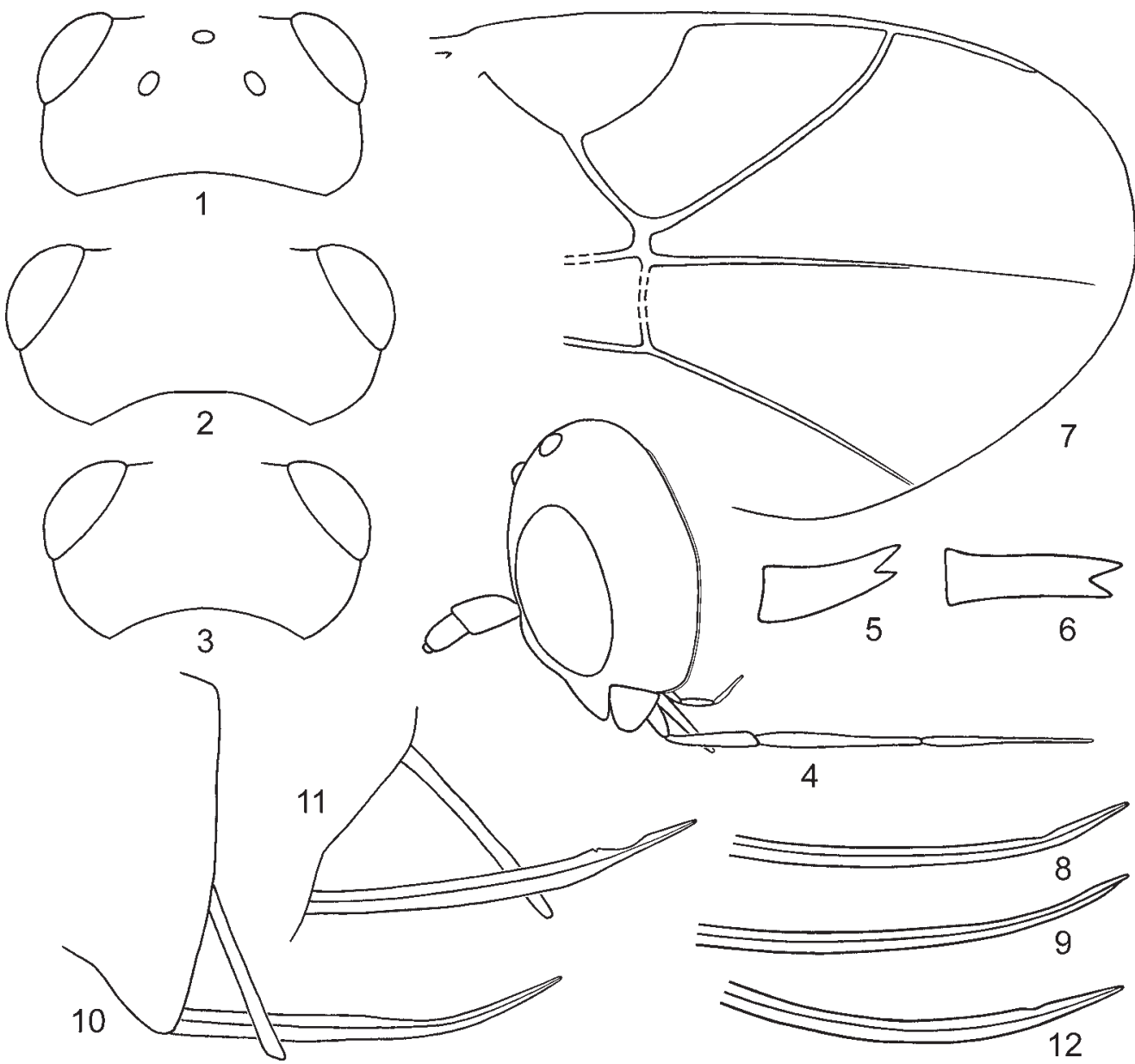

Figs 1-11. Tersilochinae, females $\mathbf{1}, 4,7, \mathbf{8}$, Palpator sicilicus gen et sp. $\mathrm{n} ; \mathbf{9}, P$ turpilucricupidus sp. $\mathrm{n} \cdot \mathbf{2}, \mathbf{1 0}$ Tersilochus abyssinicus sp. n.; 11, T. rusticulus sp. n.; 3, 5, 12, Zealochus gauldi sp. n.; 6, Z. postfurcalis sp. n. 1-3, head, dorsal view; 4, head, lateral view; 5, 6, mandible; 7, apical part of fore wing; 8-12, ovipositor, lateral view.

what shorter than eye width (Fig. 1). Antenna with 20 segments; basal flagellar segments slightly elongate; subapical segments almost as long as wide. Maxillary palpi much longer than head height; labial palpi short (Fig. 4). Mandible strongly tapered, triangular. Malar space about half of basal mandibular width. Clypeus mostly smooth, coarsely and densely punctate. Face granulate, coarsely and densely punctate. Frons, vertex and temple granulate and finely punctate.

Mesosoma $1.3 \mathrm{~mm}$ long and $0.7 \mathrm{~mm}$ wide. Mesonotum granulate and finely punctate. Mesopleuron and dorsolateral area of propodeum granulate, partly indistinctly punctate. Sternaulus very weak, situated in the anterior part of mesopleuron, about half of mesopleuron length. Propo- deum with shallow basal groove. Basal part of propodeum dorsally 0.4 times as long as apical area. Apical area round anteriorly, granulate to granulate-rugulose. Transverse carina and longitudinal carinae of apical area weak; longitudinal carinae not reaching transverse carina. Distance between propodeal spiracle and pleural carina about 3 times spiracle diameter.

Fore wing length about $3 \mathrm{~mm}$. 2-mcu vein postfurcal, mostly unpigmented (Fig. 7). Metacarp not reaching apex of fore wing. Width of pterostigma somewhat greater than length of first part of radial vein (Fig. 7).

First tergite length $0.7 \mathrm{~mm}$, posterior width $0.3 \mathrm{~mm}$. Petiole trapeziform in transverse section, striate dorsally and laterally. Glymma absent. 
Second tergite length $0.56 \mathrm{~mm}$. Thyridia distinct, twice as long as wide. Ovipositor long and thin, weakly upcurved, without teeth and with shallow dorsal subapical depression (Fig. 8); its sheath $3.1 \mathrm{~mm}$, slightly shorter than body.

Body black. Base of mandible and labial palpi brownish yellow. Maxillary palpi and tegula darkened. Legs brownish. All coxae, trochanters, trochantelli and hind femora entirely black. Fore femur basally and middle femur almost entirely darkened. Hind tibia with dark band near apex. Pterostigma light brown. Metasoma behind first tergite from yellow-brown ventro-anteriorly to dark brown or black dorso-posteriorly.

Male unknown.

\section{Palpator turpilucricupidus sp. n. (Fig. 9)}

Holotype. o, Tunisia, Hammamet, 6.IV.1964, G.J. Kerrich (BMNH).

Paratypes. $4 \sigma^{\prime \prime}$, the same data as in holotype (30" in BMNH; $1 \sigma^{\prime \prime}$ in ZISP).

Description. Female. Body length about 3.5 $\mathrm{mm}$. Head $0.7 \mathrm{~mm}$ wide, slightly prominent anteriorly and roundly narrowed posteriorly behind eyes in dorsal view. Temple somewhat shorter than eye width. Antenna with 19 segments; basal flagellar segments slightly elongate; middle and subapical segments shorter than wide or as long as wide. Maxillary palpi longer than head height. Labial palpi short. Mandible strongly tapered, triangular, punctate in its basal part. Malar space very short; mandible almost adjoin to lower orbit of eye. Clypeus mostly smooth, coarsely and densely punctate in its upper part, and with row of punctures in its lower margin. Face granulate, coarsely and densely punctate. Frons, vertex and temple granulate, finely and sparsely punctate.

Mesosoma $0.7 \mathrm{~mm}$ wide. Mesonotum granulate, finely and sparsely punctate. Mesopleuron and dorsolateral area of propodeum finely granulate (partly almost smooth) and partly indistinctly punctate. Sternaulus weak, situated in the anterior part of mesopleuron, about half of mesopleuron length. Propodeum with very shallow basal groove. Basal part of propodeum dorsally about 0.6 times as long as apical area. Apical area round anteriorly, granulate to granulate-rugulose. Transverse carina and longitudinal carinae of apical area very weak, partly indistinct; longitudinal carinae not reaching transverse carina. Distance between propodeal spiracle and pleural carina about 3 times spiracle diameter.

Fore wing length $2.6 \mathrm{~mm}$. 2-mcu vein postfurcal, unpigmented in its anterior half. Metacarp not reaching apex of fore wing. Width of pterostigma greater than length of first part of radial vein.

First tergite length $0.65 \mathrm{~mm}$, posterior width $0.22 \mathrm{~mm}$. First tergite entirely smooth; petiole tra- peziform in transverse section. Glymma absent. Second tergite length $0.5 \mathrm{~mm}$. Thyridia distinct, 2.5 times as long as wide. Ovipositor long and thin, upcurved, without teeth and without distinct subapical depression, thinner apically (Fig. 9); its sheath $2.8 \mathrm{~mm}$, slightly shorter than body.

Body black with brown hue. Base of mandible, labial palpi, tegula, pterostigma and legs brownish yellow. Maxillary palpi, all coxae, trochanters, trochantelli, fore femora basally, middle and hind femora almost entirely dark. First tergite brown. Metasoma behind first tergite from yellow ventrally to brown or dark brown dorsally.

Male. Similar to female but antenna with 1921 segments, head not prominent anteriorly behind eyes in dorsal view; distance between propodeal spiracle and pleural carina usually longer, and coloration sometimes lighter.

Etymology. The name of this species is derived from the Latin phrase "turpis lucri cupidus".

\section{Tersilochus abyssinicus sp. $n$.} (Figs 2, 10)

Holotype. \&, Ethiopia (Abyssinia), Mt. Zuquála, circa $9000 \mathrm{ft}$., beaten from trees near lake shore, 22.X.1926, Dr. H. Scott, Box 64, 1927-127 (BMNH).

Paratypes. Ethiopia, Mt. Zuquála: 5 ㅇ, with identical labels as in holotype ( 2 in BMNH, 3 \% in ZISP); 10 \% , forest near highest point, circa $9665 \mathrm{ft} ., 23 . X .1926$, Dr. H. Scott, Box 66, 1927-127 (BMNH); 1 \%, forest near top, circa 9665 ft., 25.X.1926, Dr. H. Scott, Box 68, 1927127 (BMNH); 2 \%, 2 o", in crater, circa $9000 \mathrm{ft}$., 26.X.1926, J. Olmer Cooper, Box 76, 1927-127 (BMNH); 1 ơ", circa 9000 ft., 21-25.X.1926, Dr. H. Scott, Box 64, 1927-127 (BMNH).

Description. Female. Body length about $3.3 \mathrm{~mm}$. Head $0.88 \mathrm{~mm}$ wide, strongly and roundly narrowed behind eyes in dorsal view (Fig. 2), entirely granulate and impunctate. Temple shorter than eye width (Fig. 2). Antenna with 21-22 segments, filiform; 2nd-4th flagellar segments 1.8-2.2 times, subapical segments about 1.3 tmes as long as wide. Mandible finely punctate in its basal part; upper tooth distinctly longer than lower tooth. Malar space slightly shorter than, or sometimes subequal to basal mandibular width. Clypeus smooth in its lower part and very finely granulate, finely and sparsely punctate in its upper part.

Mesosoma $1.28 \mathrm{~mm}$ long and $0.68 \mathrm{~mm}$ wide, entirely granulate and impunctate. Sternaulus upcurved, crenulate, about 2/3 of mesopleuron length, situated in the middle of mesopleuron. Propodeum usually with basal keel; sometimes with narrow basal area or with longitudinal rugulosity. Basal part of propodeum dorsally 0.30.5 times as long as apical area. Longitudinal carinae of apical area weak. Distance between propodeal spiracle and pleural carina 1.0-1.5 times spiracle diameter. 
Fore wing length about $3 \mathrm{~mm}$. 2-mcu vein postfurcal, unpigmented in its anterior part. Metacarp somewhat not reaching apex of fore wing. Width of pterostigma much less than length of first part of radial vein.

First tergite length $0.8 \mathrm{~mm}$, posterior width $0.2 \mathrm{~mm}$. Petiole distinctly striate dorsally and laterally. Glymma small, joined by weak furrow to ventral part of postpetiole. Second tergite length $0.34 \mathrm{~mm}$. Thyridia short. Ovipositor short, weakly upcurved, without teeth and dorsal subapical notch (Fig. 10); its sheath $0.46 \mathrm{~mm}$, about 0.6 times as long as first tergite.

Body black. Palpi, scape and pedicel of antenna, mandible (except for teeth), lower part of clypeus, tegula and legs brownish yellow (hind coxa darkened). Pterostigma brown. Metasoma behind first tergite brown to dark brown.

Male. Antenna wth 21 segments. Malar space shorter than in female.

Diagnosis. The new species differs from all other species of the genus in the propodeum with basal keel (sometimes indistinct), in shape of the ovipositor and in length of its sheath (Fig. 10).

\section{Tersilochus rusticulus sp. $\mathrm{n}$. (Fig. 11)}

Holotype. , Abyssinia, Mt. Zuquála, circa 9000 ft., beaten from trees near lake shore, 22.X.1926, Dr. H. Scott, Box 64, 1927-127 (BMNH).

Description. Female. Body length about $3.2 \mathrm{~mm}$. Head $0.88 \mathrm{~mm}$ wide, strongly and roundly narrowed behind eyes in dorsal view, entirely granulate and impunctate. Temple shorter than eye width. Antenna with 21 segments; all flagellar segments distinctly elongate. Malar space slightly shorter than basal mandibular width.

Mesosoma $1.3 \mathrm{~mm}$ long and $0.7 \mathrm{~mm}$ wide, entirely granulate and impunctate. Sternaulus about half of mesopleuron length, situated in the middle of mesopleuron. Propodeum with some longitudinal carinae instead of basal area. Basal part of propodeum dorsally 0.6 times as long as apical area. Distance between propodeal spiracle and pleural carina 1.5 times spiracle diameter.

Fore wing length $3.1 \mathrm{~mm}$. 2-mcu vein postfurcal, unpigmented in its anterior part. Metacarp somewhat not reaching apex of fore wing. Width of pterostigma much less than length of first part of radial vein.

First tergite length $0.78 \mathrm{~mm}$, posterior width $0.23 \mathrm{~mm}$. Petiole partly striate dorsally and laterally. Second tergite length $0.33 \mathrm{~mm}$. Thyridia short. Ovipositor short and thick, weakly upcurved (Fig. 11); its sheath $0.5 \mathrm{~mm}, 0.65$ times as long as first tergite.
Body black. Palpi, mandible (except for teeth), lower half of clypeus, tegula and legs brownish yellow (coxae slightly darkened). Base of antenna yellowish. Pterostigma light brown. Metasoma behind first tergite predominantly brown.

Male unknown.

Diagnosis. The new species is very similar to T. abyssinicus sp. n., but differs in the shape of ovipositor (Fig. 11) and somewhat longer basal part of propodeum.

Zealochus Khalaim, 2004

\section{Key to species of Zealochus Khalaim}

1. Apical area of propodeum without longitudinal carinae, narrow, 1.5 times as long as wide; 2-mcu vein postfurcal; sternaulus lacking; mandible almost not tapered (Fig. 6). - Ovipositor thin, without teeth and dorsal subapical notch, stronger upcurved apically, its sheath about twice as long as first tergite ....... $\ldots \ldots \ldots \ldots \ldots \ldots$ Z. postfurcalis sp. $n$.

- Apical area of propodeum with longitudinal carinae, as long as wide or wider; 2-mcu vein interstitial or antefurcal; sternaulus usually present; mandible distinctly tapered . . . . . . . . . . . . . . . . . 2

2. Basal part of propodeum dorsally as long as apical area or longer; lower tooth of mandible turned under upper tooth, so that mandible seeming triangular in frontal view; first tergite with glymma joined by furrow (sometimes very shallow) to ventral part of postpetiole; antenna in female clavate; ovipositor sheath about 3 times as long as first tergite . . . . . . . . . .............. Z. supergranulatus Khalaim - Basal part of propodeum dorsally distinctly shorter than apical area; lower tooth of mandible not turned under upper tooth, both teeth clearly visible in frontal view (Fig. 5); first tergite with separate glymma; antenna filiform; ovipositor sheath 1.6 times as long as first tergite .............

Zealochus gauldi sp. $\mathrm{n}$.

(Figs 3, 5, 12)

Holotype. ㅇ, New Zealand, North Canterbury, W.E. Moore, 1938-199 (BMNH).

Description. Female. Body length about 3.0 $\mathrm{mm}$. Head $0.74 \mathrm{~mm}$ wide, roundly narrowed behind eyes in dorsal view (Fig. 3), entirely granulate and impunctate. Temple shorter than eye width (Fig. 3). Antenna with 18 segments, filiform; first flagellar segment 2.5 times, second and third segments about twice as long as wide; subapical segments slightly elongate. Mandible moderately tapered (Fig. 5), punctate in its basal part; upper tooth longer than lower tooth. Malar space somewhat shorter than basal mandibular width. Clypeus small, almost entirely smooth, hardly granulate and indistinctly punctate in its upper part.

Mesosoma $1.07 \mathrm{~mm}$ long and $0.56 \mathrm{~mm}$ wide, entirely granulate and impunctate. Sternaulus weak and short, situated in the middle of mesop- 
leuron. Propodeum with not bordered basal area. Basal part of propodeum dorsally 0.65 times as long as apical area. Apical area wide; its longitudinal carinae reaching transverse carina. Distance between propodeal spiracle and pleural carina subequal to spiracle diameter.

Fore wing length $2.75 \mathrm{~mm}$. 2-mcu vein slightly antefurcal, unpigmented in its anterior part. Metacarp reaching apex of fore wing. Width of pterostigma subequal to length of first part of radial vein.

First tergite length $0.66 \mathrm{~mm}$, posterior width $0.24 \mathrm{~mm}$. Petiole distinctly striate. Postpetiole granulate anteriorly and smooth posteriorly. Glymma small, behind middle of first tergite, not joined by furrow to ventral part of postpetiole. Second tergite length $0.45 \mathrm{~mm}$. Thyridia very shallow, elongate. Ovipositor weakly upcurved, with weak dorsal subapical notch (Fig. 12); its sheath $1.07 \mathrm{~mm}$, about 1.6 times as long as first tergite.

Head predominantly black, with brown spots on inner orbits and malar space. Mesosoma with black and brown pattern. Palpi, mandible (except for teeth), clypeus, tegula and legs from yellow to brownish yellow (hind coxa brown). Scape and pedicel of antenna yellowish-brown. Pterostigma and metasoma brown (first tergite predominantly black, postpetiole brown posteriorly).

Male unknown.

Etymology. The species is named in a honour of Dr. I. Gauld, well-known specialist in Ichneumonidae.

Zealochus postfurcalis sp. $\mathrm{n}$. (Fig. 6)

Holotype. ㅇ, "New Zealand: Mt. Cook Nat. Park. Tasman Valley, 1/2 mile W. Unwin Hut. 2,300 ft. 26.i.1972”, "Tussock grass and low plants on arid hillside", “R.A.F.M.A. Mt. Cook Expend.: W.J. Knight \& P.S' Broomfield. B.M. 1972-124” (BMNH).

Description. Female. Body length about $3.4 \mathrm{~mm}$. Head $0.84 \mathrm{~mm}$ wide, roundly narrowed behind eyes in dorsal view, entirely granulate and impunctate. Temple slightly shorter than eye width. Antenna with 18 segments, filiform; first flagellar segment 2.5 times, second and third segments about twice as long as wide; subapical segments slightly elongate. Mandible almost not tapered (Fig. 6), punctate in its basal part; upper tooth longer than lower tooth. Malar space dis- tinctly shorter than basal mandibular width. Clypeus matt, almost smooth in its lower part, and very finely granulate and indistinctly punctate in its upper part.

Mesosoma $1.3 \mathrm{~mm}$ long and $0.63 \mathrm{~mm}$ wide, entirely granulate and impunctate. Sternaulus lacking. Propodeum with not bordered basal area. Basal part of propodeum dorsally 0.8 times as long as apical area. Apical area narrow, 1.5 times as long as wide, its longitudinal carinae lacking. Distance between propodeal spiracle and pleural carina subequal to spiracle diameter.

Fore wing length $3.0 \mathrm{~mm}$. 2-mcu vein slightly postfurcal, unpigmented in its anterior part. Metacarp reaching apex of fore wing. Width of pterostigma almost equal to length of first part of radial vein.

First tergite length $0.75 \mathrm{~mm}$, posterior width $0.28 \mathrm{~mm}$. First tergite almost entirely granulate (postpetiole smooth posteriorly). Glymma lacking. Second tergite length $0.3 \mathrm{~mm}$. Thyridia indistinct. Ovipositor thin (its length half the broad of first segment of hind tarsus), without teeth and dorsal subapical notch, stronger upcurved apically; its sheath $1.3 \mathrm{~mm}$, about 1.75 times as long as first tergite.

Body predominantly black. Mesosoma with black and brown pattern. Palpi, mandible (except for teeth), clypeus, scape and pedicel of antenna, tegula and legs from yellow to brownish yellow (hind coxa black). Pterostigma brown. Metasoma behind first tergite predominantly dark brown.

Male unknown.

Zealochus supergranulatus Khalaim, 2004

Khalaim, 2004: 45.

Additional material. "New Zealand: BR St. Arnaud, 650 m. 12.xii.1980", "Noyes, Valentine \& Walker”, 20" (BMNH).

\section{Acknowledgements}

I thank Suzanne Rider, courator of Hymenoptera collection of British Museum, for loan of studied material.

\section{References}

Khalaim, A.I. 2004. New tersilochines from Australia and New Zealand (Hymenoptera: Ichneumonidae, Tersilochinae). Zoosyst. Ross., 13(1): 43-45.

Received 3 November 2005. 